\title{
Sosyal Medya Platformu Seçimini Etkileyen Kriter Ağırlıklarının Bulanık DEMATEL Yöntemiyle Belirlenmesi
}

\section{Dr. Öğr. Üyesi Burcu Oralhan ${ }^{1 *}$}

Geliș tarihi: 04.09.2019

Kabul tarihi: 20.09.2019

\section{Atıf bilgisi:}

IBAD Sosyal Bilimler Dergisi

Sayı: Özel Sayı Sayfa: 408-420

Yıl: 2019

This article was checked by Turnitin. Similarity Index $22 \%$.

${ }^{1}$ Nuh Naci Yazgan Üniversitesi, Türkiye, , boralhan@nny.edu.tr,

ORCID ID 0000-0001-8905-0140

* Sorumlu yazar

\section{ÖZ}

Hızlı etkileşim günümüzde sosyal medyanın sahip olduğu en önemli özelliklerinden biridir. İșletmelerin reklam faaliyetlerinde sosyal medya, diğer pazarlama kanallarına göre daha fazla kişiye ulaşabilme imkanı sağlamaktadır. Ancak dünya genelinde sosyal medya platformlarının sayısı gün geçtikçe artmakta ve bu platformlardaki tüketici eğilimi değişiklik göstermektedir. İşletmeler tarafindan yatırım yapılacak olan reklam faaliyetine yönelik sosyal medya platformunun belirlenmesi bir çok kriterli karar verme problemidir. Sosyal medya platformu seçim problemleri çok sayıda ve çoğu zaman birbiriyle çelişen kriterler içeren karmaşık problemlerdir. Bu araştırmada Türkiye'de telekomünikasyon sektöründe öncü bir işletmenin sosyal medya platformlarının seçiminde önem arz eden kriterlerin ve etki düzeylerinin belirlenmesi ve ağırlıklarının hesaplanması amaçlanmaktadır. Ağırlıkların hesaplanmasında Bulanık DEMATEL yönteminden, durulaştırma aşamasında ise CFCS yönteminden faydalanılmıștır. Araștırma kapsamında görünüm ve algı, içerik, maliyet, üye profili, izlenim oranı ve teknik destek olmak üzere 6 kriter belirlenmiştir. Analiz sonuçlarına göre izlenme oranı $(0,185)$, görünüm ve alg1 $(0,181)$ ve üye profili $(0,170)$ kriterleri sosyal medya platformu seçiminde en fazla ağırlığa sahip ilk üç kriter olarak karşımıza çıkmıștır. $\widetilde{\mathrm{E}}_{\mathrm{i}}+\widetilde{\mathrm{F}}_{\mathrm{i}}$ değeri kriterlerin göreli önemini ifade etmektedir. $\widetilde{\mathrm{E}}_{\mathrm{i}}-\widetilde{\mathrm{F}}_{\mathrm{i}}$ değerleri pozitif olan izlenme oranı, görünüm ve alg1 ve üye profili kriterleri diğer kriterleri etkileyen grupta yer almaktadır. Dolayısıyla bu kriterlerin, diğer kriterler üzerinde en çok etkiye sahip oldukları söylenebilir. $\widetilde{\mathrm{E}}_{\mathfrak{I}}-\widetilde{\mathrm{F}}_{\mathrm{i}}$ değerleri negatif olan maliyet, içerik ve teknik destek kriterleri ise etkilenen grupta yer almaktadır. Etkilenen kriterler incelendiğinde ise $\widetilde{\mathrm{E}}_{\mathfrak{1}}-\widetilde{\mathrm{F}}_{\mathrm{i}}$ ideğeri en küçük olan maliyet kriterinin sosyal medya platform seçiminde diğer kriterlerden en çok etkilenen kriter olduğu görülmektedir. $\mathrm{Bu}$ çalışma genel olarak dijital pazarlama kanallarının seçimine, kriter ağırlıklarının ve kriterlerin etki düzeylerinin belirlenmesine yönelik yapılacak araştırmalara farklı bir bakış açısı kazandıracaktır.

Anahtar Kelimeler: Sosyal Medya, Çok Kriterli Karar Verme, Dematel. 


\section{Determining Criteria Weights That Affect Social Media Platform Selection with Fuzzy DEMATEL Approach}

\section{Asst. Prof.Dr. Burcu Oralhan ${ }^{1 *}$}

First received: 04.09 .2019

Accepted: 20.09.2019

\section{Citation:}

IBAD Journal of Social Sciences

Issue: Special Issue Pages: 408-420

Year: 2019

This article was checked by Turnitin. Similarity Index $22 \%$.

${ }^{1}$ Nuh Naci Yazgan University, Turkey, boralhan@nny.edu.tr,

ORCID ID 0000-0001-8905-0140

\section{* Corresponding Author}

\begin{abstract}
Fast interaction is one of the most important features of social media today. Social media enables businesses to reach more people in their advertising activities than other marketing channels. However, the number of social media platforms worldwide is increasing day by day and the consumer trend on these platforms is changing. Identifying the social media platform for advertising activity that will be invested by businesses is a multi-criteria decision making problem. Social media platform selection problems are complex problems with numerous and often conflicting criteria. In this research, it is aimed to determine the criteria and impact levels that are important in the selection of social media platforms of a leading business in the telecommunications sector in Turkey and to calculate their weight. Fuzzy DEMATEL method was used for calculation of weights and CFCS method was used for rinsing. Within the scope of the research, 6 criteria including appearance and perception, content, cost, member profile, impression rate and technical support were determined. According to the results of the analysis, the criteria of view rate $(0.185)$, view and perception $(0.181)$ and member profile $(0.170)$ were the top three criteria with the most weight in the selection of social media platform. The $\widetilde{\mathrm{E}}_{\mathrm{i}}+\widetilde{\mathrm{F}}_{\mathrm{i}}$ value expresses the relative importance of the criteria. Ratings, appearance and perception and member profile criteria, which have positive $\widetilde{\mathrm{E}}_{\mathrm{I}}-\widetilde{\mathrm{F}}_{\mathrm{i}}$ values, are included in the group that affects other criteria. Therefore, these criteria can be said to have the most impact on other criteria. The cost, content and technical support criteria, which have negative $\widetilde{\mathrm{E}}_{\mathrm{i}}-\widetilde{\mathrm{F}}_{\mathrm{i}}$ values, are included in the affected group. When the affected criteria are examined, it is seen that the cost criteria, which has the smallest value of $\widetilde{\mathrm{E}}_{\mathrm{i}}-\widetilde{\mathrm{F}}_{\mathrm{i}}$, is the most affected criteria among the other criteria in social media platform selection. This study will give a different perspective to research on the selection of digital marketing channels in general and the determination of criteria weights and impact levels of criteria.
\end{abstract}

Keywords: Social Media, Multi Criteria Decision Making, Dematel. 


\section{GİRIŞ̧}

Sosyal medya son yıllarda ortaya çıkan yeni bir medya olmasına rağmen, dünya çapında popüler bir şekilde kullanılmaktadır. Günümüzde işletmelerin pazarlama faaliyetleri adına sadece geleneksel medya ile yeterli kalmayıp, dijital pazarlama kanallarını da aktif hale getirmişlerdir. İletişim açısından sosyal medya, çevrimiçi bir dağıtım kanalı olarak kullanılmasının yanı sıra hizmet geliştirme, müşteriyle ilişki kurma ve topluluk içinde marka sadakati oluşturma gibi konularda da etkili bir araç olarak ifade edilebilmektedir. Etkili kullanıldığında sosyal medya, işletmelerin marka savunucularının gücünden de faydalanılmasına imkan vermektedir. Bunun yanında operasyonel faydaların yanı sira stratejik faydalar da elde edilebilmektedir Palmer ve Koenig ve Lewis, 2009; Meet the Tweet, 2009;). Sosyal medya pazarlamasının (SMP) önemini fark eden bazı işletmeler, sosyal medya platformlarının gelişim aşamasında pazarlama faaliyetleri başlatarak bu alanda öncü olmuşlardır.

Geçmişteki çalışmaların odaklandığı konular incelendiğinde dijital pazarlamaya yönelik birçok araştırmanın yapıldığ 1 görülmüştür. Araştırmalarda pazar araştırmalarının yanı sıra blog, kullanıcı, platform veya ürün incelemeleri de yapılmıştır (Ye, Law \& Gu, 2009; Chung \& Law, 2003; Chan, 2008; Law \& Ngai, 2005). Sosyal medya, Web 2.0 platformunda yer alan ve dünyanın her yerinden gelen internet kullanıcılarının fikir, içerik, düşünce, deneyim, bakış açısı ile etkileşimde bulunma, iletişim kurma ve paylaşmalarını sağlayan bir grup internet tabanlı uygulama olarak tanımlanmaktadır (Kaplan \& Haenlein, 2010; Xiang \& Gretzel, 2009; Briscoe, 2009; Scott, 2007; Tylee, 2009).

Doğru sosyal medya platformunu belirlemek ve aktif olarak kullanmak, kurumsal pazarlamacılar için riskli bir görevdir. Bu risk izlenme sıklığı, maliyeti, izleyici profili, platformun içeriği, tasarımı gibi birçok faktörden kaynaklanmaktadır. Her ne kadar sosyal medya platformu seçim problemleri doğal olarak çok sayıda ve çoğu zaman birbiriyle çelişen kriterler içeren karmaşık problemler olsa da literatürde analitik sosyal medya platformu değerlendirmesi ve seçimine yönelik yapılan çalışmalar sınırlı sayıdadır. Mevcut modellerin çoğu, farklı sosyal medya bağlantı türlerini inceleyen basit sinıflandırma çizelgeleriyle sinırlandırılmaktadır (McLellan, 2010). Sosyal medya platformunun değerlendirilmesi ve seçimi için daha sistematik ve analitik bir çerçeveye ihtiyaç vardır.

$\mathrm{Bu}$ araştırmada Bulanık DEMATEL (Decision making trial and evaluation laboratory) yöntemi kullanılarak sosyal medya platformu seçimini etkileyen kriterlerin ağılıklarının, etki düzeylerinin belirlenmesi hedeflenmektedir. Bu kapsamda girişten sonra araştırmada ikinci bölümde ilgili literatür taraması yer almaktadır. Üçüncü bölümde araştırmada kullanılan bulanık DEMATEL ve durulaştırma için kullanılan CFCS (Converting Fuzzy data into Crisp Scores) yöntemin ayrıntıları sunulmaktadır. Dördüncü bölümde ise Türkiye'de önde gelen bir Telekomünikasyon firması pazarlama yöneticileriyle görüşülerek gerçek dünyadan bir vaka çalışmasına yer verilmektedir. Son bölümde ise sonuçlar ve gelecekteki araştırma önerileri sunulmaktadır.

\section{LITERATÜR ARAŞTIRMASI}

Sosyal medya, bilgiyi merkezi olmayan kullanıcı düzeyinde içerik ve sosyal etkileşim sağlamak için kullanılan internet platformlarıdır (Abrahams vd., 2012). Sosyal aktivite ve yakın topluluk katılımı gibi çeşitli sosyal etkileşimlere imkan sağlayan sosyal medya erişilebilir ve ölçeklenebilir niteliktedir (Li ve Shiu, 2012). En yaygın kullanılan sosyal medya mekanizmaları, ürün veya hizmet inceleme web siteleri, bloglar, sohbet odaları, tartışma panoları ve Facebook, Twitter, Instagram, Snapchat, LinkedIn, Google+ ve YouTube gibi sosyal ăg siteleri çevrimiçi forumlardır (Mangold \& Faulds, 2009; Kaplan ve Haenlein, 2010). Sosyal medya pazarlaması, insanları bir sosyal ağın parçası olarak ele alır ve ürün veya hizmet almak/satmak için insanlar arasındaki sosyal ilişkileri ve sosyal etkileri kullamaktadır (Wang, Wang ve Farn, 2009). Beş farklı özellik sosyal medyayı güçlü bir pazarlama aracı yapmaktadır.

1.Katılım: Sosyal medyaya katılımı ve geri bildirimi teşvik eder (Durugbo, 2012);

2.Açıklık: Sosyal medya hizmetlerinin çoğu oylamayı, yorumlamayı ve bilgi paylaşımını özendirerek geri bildirime ve katılmaya açıktır (Bertot, Jaeger ve Grimes, 2010);

3.Konuşma: Geleneksel medya bir mesaj yayınlamakla ilgilidir, sosyal medya ise iki yönlü bir konuşmadır (Özyurt ve Köse, 2010); 
4.Topluluk: Topluluklar sosyal medya aracılı̆̆ıyla hızlı bir şekilde oluşturabilir ve etkili bir şekilde sohbet kurulabilir (Kim ve Ahmad, 2013);

5.Bağl1lık: Sosyal medya, diğer sitelere, kaynaklara ve insanlara bağlantılardan faydalanarak bağlantılar üzerinde büyür (Grieve vd., 2013).

$\mathrm{Bu}$ belirgin özelliklere sahip olan sosyal medya pazarlaması, birkaç pratik ama önemli avantaj sağlamaktadır. Sosyal medya pazarlamacılığı, şirketlerin marka bilinirliğini artırmalarına (Qualman, 2009), dünya çapında milyonlarca izleyiciye ulaşmalarına yardımcı olmakta (Trusov ve diğerleri, 2009) ve pazarlama maliyetlerinde tasarruf etmelerini sağlamaktadır (Weber, 2007; Michaelidou, Siamagka ve Christodoulides, 2011).

Sosyal medya platformu seçim problemleri, birçok kritere sahip karmaşık problemlerdir. Çok kriterli karar verme (ÇKKV) yöntemleri, çok kriterli problemleri çözmek için yaygın olarak kullanılmaktadır. Her bir ÇKKV yöntemi, önceden seçilmiş birkaç alternatif arasından en iyisini seçmek için farklı bir yaklaşım sunmaktadır (Janic ve Reggiani, 2002). ÇKKV yöntemleri, karar vericilerin (KV) karşılaştıkları sorunları, kendi ve diğer tarafların değer sistemlerini ve sonuçta tercih edilen bir eylem planını belirlemede yol gösterecek organizasyonel değerleri ve hedefleri öğrenmelerine yardımcı olmaktadır (Doumpos ve Zopounidis, 2002). ÇKKV problemlerinin çözülmesinin optimal bir çözüm arayışı değil, KV'lerin sorunlarına dahil olan karmaşık yarg1 ve verileri yönetmelerine ve kabul edilebilir bir çözüme ilerlemelerine yardımcı olmaktadır (Roy, 1990).

Çok kriterli karar verme analizleri genellikle gerçek hayatta karşılaşılan problemler üzerine modellenmiştir. $\mathrm{Bu}$ analizler her probleme uygulanabilecek standart bir araç değildir (Vincke, 1992). Bu modeller genel çerçevenin veya yönteminin seçimine, problemin niteliğine, seçim türlerine, ölçüm ölçeklerine, nitelikler arasındaki bağımlılığa, belirsizlik tipine, KV'lerin beklentilerine, mevcut verilerin ve kararların miktarına ve kalitesine göre dikkatlice seçilmelidir (Vincke, 1992). Sosyal medya platformu seçimine yönelik 2013 yılında yapılan bir çalışmada hibrit çerçevede süreç değerlendirilmiştir. Bulanık Analitik Ağ Süreci ve gri ilişki yöntemiyle (COPRAS-G) ile birleştirilmiştir. ANP ve bulanık küme teorisi, sosyal medya platformu seçim kriterlerinin ağırlıklarının hesaplanması, COPRAS-G ise alternatiflerin seçimi için kullanılmıştır.

$\mathrm{Bu}$ araştırmada sosyal medya platformlarının seçiminde önem arz eden kriterlerin ağırlıklarının hesaplanması ve etki düzeyinin belirlenmesi amaçlanmaktadır. Ağılıkların hesaplanmasında bulanık DEMATEL yönteminden, durulaştırma aşamasında ise CFCS yönteminden faydalanılmıştır.

\section{METODOLOJI}

DEMATEL yöntemi, kriterlerin önem derecelerini ve kriterler arasındaki mevcut yapı ve ilişkileri tanımlaması amacıyla Cenevre Battelle Memorial Araştırma Merkezi tarafından geliştirilmiş etkili bir teknik olarak bilinmektedir (Gabus \& Fontela, 1972, 1973). Spesifik olarak, DEMATEL metodu, ilgili faktörleri neden grubu ve etki grubuna ayırabilecek diyagramlara dayanmaktadır. DEMATEL yöntemi sayesinde faktörlerin arasındaki neden-etki ilişkileri görselleştirilebilmektedir. Elde edilen bu ilişkilerin önem derecelerini ortaya koymak, ilgili problemin çözümü için gereken önemli bir aşamadır (Ada vd., 2011).

Literatürde DEMATEL'in başarıyla uygulandığ çalışmalara rastlamak mümkündür. Örneğin, havayolu güvenliği değerlendirilmesinde (Liou vd., 2007), hastane servis kalitesinin belirlenmesinde (Shieh, 2010), bilgi yönetimi stratejilerinin seçiminde (Wu,2008), altı sigma proje seçiminde (Büyüközkan ve Öztürkcan, 2010), dış kaynak kullanımı sağlayıcısı seçiminde (Liou ve Chuang, 2010), yeşil tedarik zinciri yönetiminde tedarikçi seçimi karbon yönetimi modelinin geliştirilmesinde (Hsu vd.,2013) işletme bölümü öğrencilerinin meslek seçimini etkileyen faktörleri değerlendirilmesinde de (Akın, 2017) DEMATEL tekniğinden faydalanılmıştır. Akın (2017) Dematel yöntemini kullanarak işletme öğrencilerinin meslek tercihine etki eden faktörlerin ağılık değerlerine göre yapılan sıralamada en yüksek etkiye sahip faktörden en düşük etkiye sahip faktöre doğru, yükselme imkânları, iş güvencesi, mesleki kazanç, yetki ve üstünlük, esnek çalışma koşulları, kişisel yetenekler, iş olanakları, aile beklentisi, sosyal imkânlar ve alınan dersler şeklinde belirlenmiştir. Farklı bir çalışmada Shieh vd. (2010) Tayvan'daki bir hastanede, hastanenin hizmet kalitesinde etkili olan temel başarı faktörlerini belirlemek 
için DEMATEL yöntemini kullanmıştır. Çalışmada iyi iletişim becerisine sahip personeli ve acil problem çözme becerisine sahip personelin hizmet kalitesi için 2 önemli kriter olduğu ortaya konulmuştur. Liou ve Chuang (2010) DEMATEL metodu yardımıyla kriterler arasında bağımlı ilişkiler kurarak bir melez ÇKKV modeli geliştirmişlerdir. Her bir kriterin göreli ağırlıklarını belirlemek amacıyla ANP ve alternatiflerin sıralanması için VIKOR yöntemini kullanmışlardır.

DEMATEL yönteminin bulanık mantıkla bütünleşik olarak ilk kez bulanık mantığın kurucusu olarak gösterilen Lotfi A. Zadeh (1965), tarafindan uygulanmıştır (Özdemir, 2016). Bulanık DEMATEL oldukça yeni bir teknik olmasına karşın, çalışmaların sayısında son yıllarda artış gözlenmektedir. Bulanık DEMATEL'de yeşil tedarik zinciri yönetimi uygulamalarının değerlendirilmesi (Lin, 2013), enteraktif ticaretin değerlendirilmesi (Wang, 2012), yer seçimi (Kuo ,2011), kamyon seçimi (Baykasoglu vd.,2013), olağanüstü yönetimde kritik başarı faktörlerinin belirlenmesi (Zhou vd.,2011), bilim ve teknoloji için insan kaynakları değerlendirmesi (Choua vd.,2012), limanlarda yaşanan iş kazalarının sebeplerinin incelenmesi gibi birçok çalışma yapılmıştır (Özdemir, 2016). DEMATEL metodunu uygulamak için Fontela ve Gabus (1976) tarafindan kullanılan versiyonun Wu ve Lee tarafindan (2007) geliştirilmiş hali ve adımları aşağıdaki gibidir;

\section{Adım: Bulanık Başlangıç Direk İliş̧ki Matrisinin Oluşturulması}

Karar vericilerin kriterlere yönelik görüşlerinin ikili karşılaştırmalar yapılarak üçgensel bulanık sayılara dönüştürülmesi için bulanık değerlendirme ölçeği oluşturulur. Bulanık değerlendirme ölçeği beş seviye olarak belirlenebilir. Bu çalışmada belirlenen dilsel değişkenler ve üçgensel bulanık sayı skalası Tablo 1 'deki gibi belirlenmiştir.

Tablo 1. Bulanık Değerlendirme Ölçeği (Wu ve Lee, 2007)

\begin{tabular}{|c|c|}
\hline Dilsel Değişkenler & Üçgensel Bulanık Sayılar \\
\hline Etki Yok (0) & $(0 ; 0 ; 0,25)$ \\
\hline Çok Az Etkili (1) & $(0 ; 0,25 ; 0,50)$ \\
\hline Az Etkili (2) & $(0,25 ; 0,50 ; 0,75)$ \\
\hline Yüksek Etkili (3) & $(0,50 ; 0,75 ; 1)$ \\
\hline Çok Yüksek Etkili (4) & $(0,75 ; 1 ; 1)$ \\
\hline
\end{tabular}

Bir $\widetilde{\mathrm{A}}$ kümesinde üçgensel bulanık sayılar $(\mathrm{l}, \mathrm{m}, \mathrm{u})$ olarak belirtilebilir $(\mathrm{l} \leq \mathrm{m} \leq \mathrm{u})$. Üyelik fonksiyonu aşağıdaki gibi tanımlanır:

$$
\mu_{\tilde{\mathrm{A}}(\mathrm{x})}=\left\{\begin{array}{cc}
0, & \mathrm{x}<\mathrm{l} \\
(\mathrm{x}-\mathrm{l}) /(\mathrm{m}-\mathrm{l}), & \mathrm{l} \leq \mathrm{x} \leq \mathrm{m} \\
(\mathrm{u}-\mathrm{x}) /(\mathrm{u}-\mathrm{m}), & \mathrm{m} \leq \mathrm{x} \leq \mathrm{u} \\
0, & \mathrm{x}>\mathrm{u}
\end{array}\right.
$$

$\widetilde{\mathrm{Z}}_{\mathrm{ij}}$ i kriterinin j kriterini etkileme derecesi olan bulanık direk ilişki matrisi $\widetilde{\mathrm{Z}}=\left[\widetilde{\mathrm{z}}_{\mathrm{ij}}\right]_{\mathrm{nxn}}$ ile gösterilmektedir. Kriterler arasında etki ve neden açısından ikili karşılaştırmalar ile elde edilen (nxn) boyutlu bir matristir.

\section{Adım: Normalleştirilmiş Bulanık Direk İlişki Matrisinin Elde Edilmesi}

Normalleştirilmiş bulanık direk ilişki matrisi $\left(\widetilde{\mathrm{A}}=\left[\widetilde{\mathrm{a}}_{\mathrm{ij}}\right]_{\mathrm{nxn}}\right)$ ile gösterilmektedir. Aşağıdaki gibi elde edilir.

$$
\begin{gathered}
\widetilde{a}_{\mathrm{ij}}=\frac{\widetilde{Z}}{\mathrm{~s}}=\left(\frac{\mathrm{l}_{\mathrm{ij}}}{\mathrm{s}}, \frac{\mathrm{m}_{\mathrm{ij}}}{\mathrm{s}}, \frac{\mathrm{u}_{\mathrm{ij}}}{\mathrm{s}}\right) \\
\mathrm{s}=\max _{1 \leq i \leq n}\left(\sum_{\mathrm{j}=1}^{\mathrm{n}} \mathrm{l}_{\mathrm{ij}}\right) \quad \mathrm{s}=\max _{1 \leq \mathrm{i} \leq \mathrm{n}}\left(\sum_{\mathrm{j}=1}^{\mathrm{n}} \mathrm{m}_{\mathrm{ij}}\right) \quad \mathrm{s}=\max \left(1 \leq \mathrm{i} \leq \mathrm{n} \sum_{\mathrm{j}=1}^{\mathrm{n}} \mathrm{u}_{\mathrm{ij}}\right)
\end{gathered}
$$




\section{Adım: Toplam Bulanık Illişki Matrisinin Hesaplanması}

I birim matris olarak olmak üzere normalleştirilmiş bulanık direk ilişki matrisi aşağıdaki gibi elde edilir.

$$
\widetilde{T}=\widetilde{A}+\widetilde{A}^{2}+\widetilde{A}^{3}+\cdots=\sum_{\tilde{I}=1}^{\infty} \tilde{A}^{i}=\tilde{A}(I-\widetilde{A})^{-1}
$$

Burada $\widetilde{\mathrm{T}}=\left[\tilde{\mathrm{t}}_{\mathrm{ij}}\right]_{\mathrm{nxn}}$ ile gösterilir ve $\tilde{\mathrm{t}}_{\mathrm{ij}}=\left(\mathrm{t}_{\mathrm{ij}, \mathrm{l}}, \mathrm{t}_{\mathrm{ij}, \mathrm{m}}, \mathrm{t}_{\mathrm{ij}, \mathrm{u}}\right)$ i kriterinin $\mathrm{j}$ kriterine karşı karar vericinin belirlediği toplam etki derecesini gösterir.

\section{Adım: Gönderici ve Alıcı Grupların Bulunması}

Satırların toplamı ve sütunların toplamı, $\widetilde{T}$ toplam ilişki matrisi içinde ayrı ayrı olarak incelenir. Burada;

$$
\begin{array}{rl}
\widetilde{\mathrm{T}}=\left[\tilde{\mathrm{t}}_{\mathrm{ij}}\right]_{\mathrm{nxn}} & i, j=1,2 \ldots . \\
\widetilde{\mathrm{E}}_{\mathrm{i}}=\sum_{\mathrm{j}=1}^{\mathrm{n}} \mathrm{t}_{\mathrm{ij}} \\
\widetilde{\mathrm{F}}_{\mathrm{i}}=\sum_{\mathrm{i}=1}^{\mathrm{n}} \mathrm{t}_{\mathrm{ij}}
\end{array}
$$

$\widetilde{\mathrm{E}}_{\mathrm{i}} \mathrm{i}$ kriterinin diğer kriterlere gönderdiği toplam etkiyi, $\widetilde{\mathrm{F}}_{\mathrm{i}}$ ise diğer kriterlerden i kriterinin aldığ toplam etkiyi gösterir. $(\widetilde{E}+\widetilde{F})$ toplamı i kriterinin hem verdiği hem de aldığı toplam etkisini yani önem derecesini ifade etmektedir. $(\widetilde{E}-\widetilde{\mathrm{F}})$ farkı ise i kriterinin sisteme sağladığ 1 etkiyi göstermektedir. $(\widetilde{\mathrm{E}}-\widetilde{\mathrm{F}})$ pozitif olduğunda i kriteri gönderici, negatif olduğunda alıcı olarak tanımlanabilir (Wu ve Lee, 2007; Aksakal ve Dağdeviren, 2010). Eğer i kriteri için $(\widetilde{\mathrm{E}}-\widetilde{\mathrm{F}})$ pozitif değer almışsa, i kriterinim diğerleri üzerinde daha yüksek etkiye ve daha yüksek önceliğe sahip olduğu söylenebilir. Tersi durumda da daha az etkiye ve daha düşük önceliğe sahip olduğu ifade edilebilir (Aksakal ve Dağdeviren, 2010).

\section{Adım: Durulaştırma (defuzzifikasyon)}

Olasılık dağılımının dikey veya yatay yayılımını inceleyerek karar veren farklı durulaştırma yöntemleri literatürde mevcuttur (Oussalah, 2002). En yaygın kullanılan durulaştırma yöntemi Centroid (Ağırlık Merkezi) yöntemidir (Yager ve Filev, 1994), ancak bu, farklı şekillere fakat aynı değere sahip iki bulanık sayı arasında ayrım yapmamaktadır. Bu nedenle, çalışmada CFCS (Converting Fuzzy data into Crisp Scores) defuzzification yöntemi kullnılmıştır. Bunun nedeni, CFCS yönteminin Centroid yönteminden daha iyi bir değer verebilmesidir.

Opricovic ve Tzeng (2003) tarafindan önerilen CFCS metodu sol ve sağ puanların bulanık minimum ve maksimum tarafindan belirlenmesi prosedürüne dayanmakta ve toplam puan ağırlıklı ortalama olarak belirlenmektedir. CFCS yöntemi beş aşamalı bir algoritmaları içermektedir.

a. Normalizasyon;

$$
\begin{gathered}
x l_{i j}^{k}=\left(l_{i j}^{k}-\min l_{i j}^{k}\right) / \Delta_{\min }^{\max } \\
x m_{i j}^{k}=\left(m_{i j}^{k}-\min l_{i j}^{k}\right) / \Delta_{\min }^{\max } \\
x u_{i j}^{k}=\left(u_{i j}^{k}-\min l_{i j}^{k}\right) / \Delta_{\min }^{\max } \\
\Delta_{\min }^{\max }=\operatorname{maxr}_{i j}^{k}-\min _{i j}^{k}
\end{gathered}
$$

b. Sol (ls) ve să̆ (us) normalize edilmiş değeri hesaplanması

$$
\begin{gathered}
x l s_{i j}^{k}=x m_{i j}^{k} /\left(1+x m_{i j}^{k}-x l_{i j}^{k}\right) \\
\mathrm{s} x u s_{i j}^{k}=x u_{i j}^{k} /\left(1+x u_{i j}^{k}-x m_{i j}^{k}\right)
\end{gathered}
$$

c. Normalize edilmiş net değerin hesaplanması

$$
x_{i j}^{k}=\left[x l s_{i j}^{k}\left(1-x l s_{i j}^{k}\right)+x u s_{i j}^{k} * x u s_{i j}^{k}\right] /\left[1-x l s_{i j}^{k}+x u s_{i j}^{k}\right]
$$

d. Net değerlerin hesaplanmast 


$$
z_{i j}^{k}=\min l_{i j}^{k}+x_{i j}^{k} \Delta_{\min }^{\max }
$$

e. Net değerlerin entegre edilmesi

$$
z_{i j}=\frac{1}{p}\left(z_{i j}^{1}+z_{i j}^{2}+\cdots+z_{i j}^{p}\right)
$$

Burada $p$ her bir karar vericiyi ifade etmektedir.

\section{Adım: Kriter Ağırlıklarının Belirlenmesi}

Durulaştırılmış matrisin bulunması, eşik değerinin belirlenmesine imkan vermektedir. $\left(\widetilde{\mathrm{E}}_{\mathrm{i}}-\widetilde{\mathrm{F}}_{\mathrm{i}}\right)$ ve $\left(\widetilde{E}_{\mathrm{I}}-\widetilde{\mathrm{F}}_{\mathrm{i}}\right)$ ile neden etki diyagramı elde edilebilir ve analiz edilebilir. Kriter ağırlıkları aşağıdaki gibi hesaplanır. Kriter ağırlıkları sıfır ve bir arasındadır ve kriter toplamları bire eşit olmalıdır.

$$
\begin{gathered}
w_{i}=\sqrt{\left(\widetilde{\mathrm{E}}_{\mathrm{i}}+\widetilde{\mathrm{F}}_{\mathrm{i}}\right)^{2}+\left(\widetilde{\mathrm{E}}_{\mathrm{i}}-\widetilde{\mathrm{F}}_{\mathrm{i}}\right)^{2}} \\
w_{\mathrm{i}}=\frac{\mathrm{w}_{\mathrm{i}}}{\sum_{\mathrm{i}=1}^{\mathrm{n}} \mathrm{w}_{\mathrm{i}}}
\end{gathered}
$$

\section{UYGULAMA}

\subsection{Araştırmanın Amacı}

Telekomünikasyon sektöründe reklam ve tanıtım faaliyetlerinde geleneksel ve dijital pazarlama kanalları yoğun olarak kullanılmaktadır. Bu çalışmada Telekomünikasyon sektöründe yer alan Türkiye'nin önde gelen bir işletmesinin ürünlerini ve kampanyalarını pazarlamak için sosyal medya platformunun seçiminde, seçimi etkileyen kriterlerin belirlenmesi ve kriter ağıllıklarının hesaplanması amaçlanmıştır. Türkiye genelinde çalışan telekomünikasyon pazarlama yöneticilerine yönelik gerçekleştirilen çalışma, sektöre genel bir bakıș açısı kazandıracaktır. Günümüzde birçok sosyal medya platformunu pazarlama kanalı olarak kullanan veya kullanmayı planlayan farklı sektörlerde yer alan işletmeler içinde kriterlerin etki düzeylerinin elde edebilmesine imkan sağlayan bu araştırma yapacakları farklı çalışmalarda ışık tutacaktır.

\subsection{Araştırmanın Modeli}

Geleneksel medya platformlarında editör kalitesi, izleyici kitlesi, teknik özellikler ve hedef popülasyon gibi platform seçimini etkileyen birçok faktör vardır (Kotler, Fitzroy \& Shaw, 1980). Araştırma ekibinin literatür araştırmaları, tecrübeleri ve işletme stratejileri doğrultusunda sosyal medya platformlarını değerlendirmek için altı kriter belirlenmiştir. Sosyal medya pazarlamasında içerik oluşturma ve düzenleme, strateji yürütme ve etki analizi platformlar arasındaki incelenecek ana faaliyetleri oluşturmaktadır. $\mathrm{Bu}$ kapsamda yapılan beyin firtınası ve değerlendirmeler sonucunda platformların görünüm ve alg1, içerik, maliyet, üye profili ve izlenim oranı (Ngai, 2003) ve teknik destek olmak üzere 6 kriter belirlenmiştir.

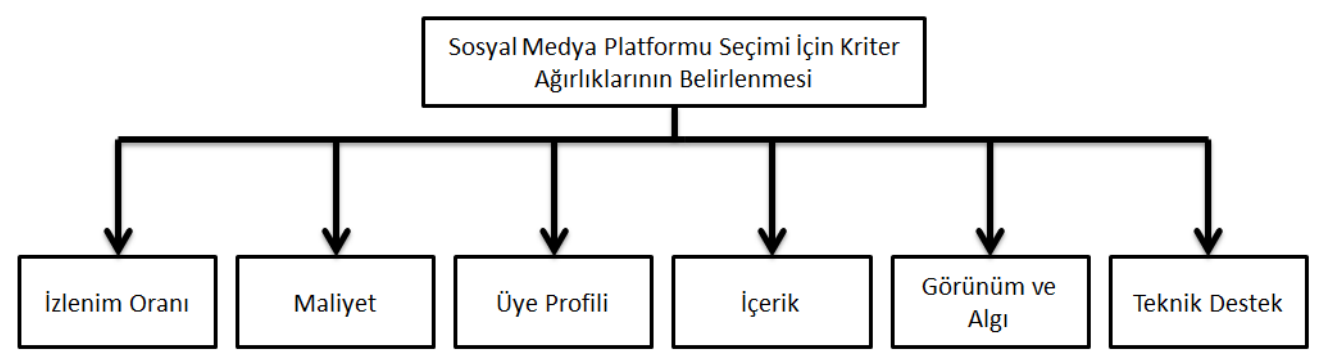

Şekil 1. Araştırmanın Modeli

Araştırma kapsamında belirlenen model Şekil 1'deki gibi oluşturulmuştur. Belirlenen kriterler, kriter kodları ve açıklamaları Tablo 2'de yer almaktadır. 
Tablo 2. Araştırmada Kullanılan Kriterler, Kodları ve Açıklamaları

\begin{tabular}{|l|l|l|}
\hline Kod & Kriter & Açılama \\
\hline C1 & $\begin{array}{l}\text { İlenim } \\
\text { Oranı: }\end{array}$ & $\begin{array}{l}\text { Reklamı gösteren sayfanın her görüntülendiğinde ortaya çıkan veridir. Reklam } \\
\text { verenlere/verecek olanlara platformdaki izlenim hakkında fikir vermektedir. Bu } \\
\text { oran sayfaya erişilme sayısını içermektedir. İzlenim oranı arttıça reklamın } \\
\text { potansiyel müşteriler tarafından görülme şansının artması anlamına gelmektedir } \\
\text { (Ngai, 2003). }\end{array}$ \\
\hline C2 & Maliyet: & $\begin{array}{l}\text { Platformun tıklama sayısına bağlı olarak bin kişi başına maliyet olarak } \\
\text { değerlendirilerek ücret almasıdır (Ngai, 2003). }\end{array}$ \\
\hline C3 & $\begin{array}{l}\text { Üye } \\
\text { Profili: }\end{array}$ & $\begin{array}{l}\text { Ziyaretçilerin hedef müşteri profiline yaş ve eğitim düzeyi açısından ne kadar } \\
\text { uyumlu olup olmadığını göstermektedir (Ngai, 2003). }\end{array}$ \\
\hline C4 & $\begin{array}{l}\text { I̧çerik: } \\
\text { İçerik, platformun içeriğinin kalitesini tanımlamak için kullanılan bir terimdir. } \\
\text { Burada bilginin çeşitliliği ve güvenilirliği değerlendirilmektedir (Ngai, 2003). }\end{array}$ \\
\hline C5 & $\begin{array}{l}\text { Görünüm } \\
\text { ve Alg1: }\end{array}$ & $\begin{array}{l}\text { Tasarım ve kullanıcı dostluğu unsurlarına bağlıdır. Bu kriterler özneldir, ancak } \\
\text { deneyimlere ve değerlendirmelere göre belirlenmektedir (Ngai, 2003). }\end{array}$ \\
\hline C6 & $\begin{array}{l}\text { Teknik } \\
\text { Destek: }\end{array}$ & $\begin{array}{l}\text { Platformda verilecek reklamlar için katkıda bulunabilecek çalışmalar, ihtiyaçlar, } \\
\text { problemler halinde platform yöneticileriyle iletişime geçilerek, çözümlere yönelik } \\
\text { hizmetin, danışmanlığın, geliştirici faaliyetlerin sağlanmasına yönelik destek } \\
\text { türüdür. }\end{array}$ \\
\hline
\end{tabular}

\subsection{Analiz ve Bulgular}

Bu çalışmada bulanık DEMATEL yöntemi ve durulaştırma aşamasında kullanılan CFCS metoduna göre uygulama gerçekleştirilmiştir. Karar vericiler Tablo 2'de belirtilen kriterleri Tablo 1'de verilen değişkenleri kullanarak kriterler arasında direk etki değerlendirmeleri yapmıştır. Örnek bir karar vericinin değerlendirmeleri Tablo 3'de yer almaktadır.

Tablo 3. Bir Karar Verici İçin İkili Karşılaştırma Matrisi

\begin{tabular}{|c|c|c|c|c|c|c|}
\hline KRITER & C1 & C2 & C3 & C4 & C5 & C6 \\
\hline C1 & 0 & 3 & 1 & 4 & 3 & 2 \\
\hline C2 & 2 & 0 & 1 & 2 & 2 & 2 \\
\hline C3 & 2 & 2 & 0 & 3 & 2 & 2 \\
\hline C4 & 3 & 3 & 3 & 0 & 2 & 2 \\
\hline C5 & 3 & 3 & 4 & 3 & 0 & 2 \\
\hline C6 & 2 & 2 & 2 & 2 & 2 & 0 \\
\hline
\end{tabular}

Bulanık DEMATEL yönteminde durulaştırma aşaması için CFCS metodunda yer alan Eş.(6) ve Eş.(10) arasındaki tüm aşamalar onsekiz karar verici için uygulanmıştır. Eş. (11) ile net değerlerin entegrasyonu karar vericilerin ortalamaları alınarak sağlanmıştır. Eş. (1) ve (2) kullanılarak normalleştirilmiş direk ilişki matrisi $\widetilde{A}$ Tablo 4'teki gibi elde edilmiştir.

Tablo 4. Normalleştirilmiş Direk İlişki Matrisi

\begin{tabular}{|c|c|c|c|c|c|c|}
\hline KRITER & C1 & C2 & C3 & C4 & C5 & C6 \\
\hline C1 & 0,009 & 0,210 & 0,150 & 0,231 & 0,210 & 0,190 \\
\hline C2 & 0,069 & 0,009 & 0,089 & 0,110 & 0,110 & 0,110 \\
\hline C3 & 0,110 & 0,190 & 0,009 & 0,170 & 0,150 & 0,150 \\
\hline C4 & 0,130 & 0,130 & 0,130 & 0,009 & 0,130 & 0,089 \\
\hline C5 & 0,130 & 0,190 & 0,210 & 0,150 & 0,009 & 0,170 \\
\hline C6 & 0,089 & 0,089 & 0,089 & 0,089 & 0,089 & 0,009 \\
\hline
\end{tabular}

Elde edilen normalleştirilmiş direk ilişki matrisinin bulanık sayıları kullanılarak Eş. (3) uygulanarak toplam bulanık ilişki matrisin T̃ elde edilmiştir. 
Tablo 5. Toplam Bulanık İlişki Matrisi

\begin{tabular}{|c|c|c|c|c|c|c|}
\hline KRİTER & C1 & C2 & C3 & C4 & C5 & C6 \\
\hline C1 & 0,299 & 0,220 & 0,329 & 0,311 & 0,368 & 0,228 \\
\hline C2 & 0,597 & 0,230 & 0,495 & 0,399 & 0,530 & 0,293 \\
\hline C3 & 0,489 & 0,272 & 0,289 & 0,356 & 0,488 & 0,261 \\
\hline C4 & 0,582 & 0,304 & 0,454 & 0,271 & 0,470 & 0,278 \\
\hline C5 & 0,540 & 0,290 & 0,417 & 0,360 & 0,323 & 0,264 \\
\hline C6 & 0,534 & 0,297 & 0,425 & 0,334 & 0,472 & 0,195 \\
\hline
\end{tabular}

Gönderici ve alıcı grupların tespiti için Eş. (4) ve Eş.(5) kullanılarak $\widetilde{E}_{\mathrm{I}}$ ve $\widetilde{F}_{\mathrm{i}}$ değerleri, sonrasında $\widetilde{\mathrm{E}}_{\mathrm{I}}-\widetilde{\mathrm{F}}_{\mathrm{i}}$ ve $\widetilde{\mathrm{E}}_{\mathrm{I}}+\widetilde{\mathrm{F}}_{\mathrm{i}}$ değerleri hesaplanmıştır. Eş. (12) ve (13) kullanılarak kriter ağırlıkları elde edilmiştir. Analiz sonucunda tespit edilen kriter ağırlıkları Tablo 5'de sunulmuştur.

Tablo 5. Kriterlerin Etki Seviyelerinin ve Ağırlıklarının Belirlenmesi

\begin{tabular}{|c|c|c|c|c|c|}
\hline KRITER & $\widetilde{\mathbf{E}}_{\hat{I}}$ & $\widetilde{\mathbf{F}}_{\mathrm{i}}$ & $\widetilde{\mathbf{E}}_{\mathrm{I}}+\widetilde{\mathbf{F}}_{\mathbf{i}}$ & $\widetilde{\mathbf{E}}_{\mathrm{I}}-\widetilde{\mathbf{F}}_{\mathbf{i}}$ & $W_{\text {i }}$ (Ăğırlıklar) \\
\hline C1 & 3,042 & 1,755 & 4,797 & 1,286 & 0,185 \\
\hline C2 & 1,614 & 2,545 & 4,159 & $-0,930$ & 0,158 \\
\hline C3 & 2,409 & 2,155 & 4,565 & 0,254 & 0,170 \\
\hline C4 & 2,030 & 2,359 & 4,389 & $-0,329$ & 0,164 \\
\hline C5 & 2,652 & 2,195 & 4,847 & 0,458 & 0,181 \\
\hline C6 & 1,518 & 2,257 & 3,774 & $-0,739$ & 0,143 \\
\hline
\end{tabular}

Tablo 5'de kriterlerin için $\widetilde{\mathrm{E}}_{\mathrm{I}}-\widetilde{\mathrm{F}}_{\mathrm{i}}$ ve $\widetilde{\mathrm{E}}_{\mathrm{I}}+\widetilde{\mathrm{F}}_{\mathrm{i}}$ değerleri ile oluşturulan etki değerleri ve ağırlıkları görülmektedir. Buna göre sosyal medya platform seçimini etkileyen kriterlerden, izlenme oranı, görünüm ve alg1 ve üye profili kriterleri en fazla ağırlığa sahip ilk üç kriter olarak karşımıza çıkmıştır. Şekil 2'de yer alan etki diyagramında da görüldüğü üzere, $\widetilde{\mathrm{E}}_{\mathfrak{i}}-\widetilde{\mathrm{F}}_{\mathrm{i}}$ değerleri pozitif olan izlenme oran1, görünüm ve alg1 ve üye profili kriterleri etkileyen grupta yer almaktadır. Dolayısıyla bu kriterlerin, diğer kriterler üzerinde en çok etkiye sahip olduklarını söylemek mümkündür. $\widetilde{E}_{\mathrm{I}}-\widetilde{\mathrm{F}}_{\mathrm{i}}$ değerleri negatif olan maliyet, içerik ve teknik destek kriterleri ise etkilenen grupta yer almaktadır. Etki diyagramı yardımıyla kriterler arasındaki etkileşimler belirlenmektedir. Etkilenen kriterler incelendiğinde ise $\widetilde{\mathrm{E}}_{\mathfrak{I}}-\widetilde{\mathrm{F}}_{\mathrm{i}}$ değeri en küçük olan maliyet kriterinin, diğer kriterlerden en çok etkilenen kriter olduğu görülmektedir.

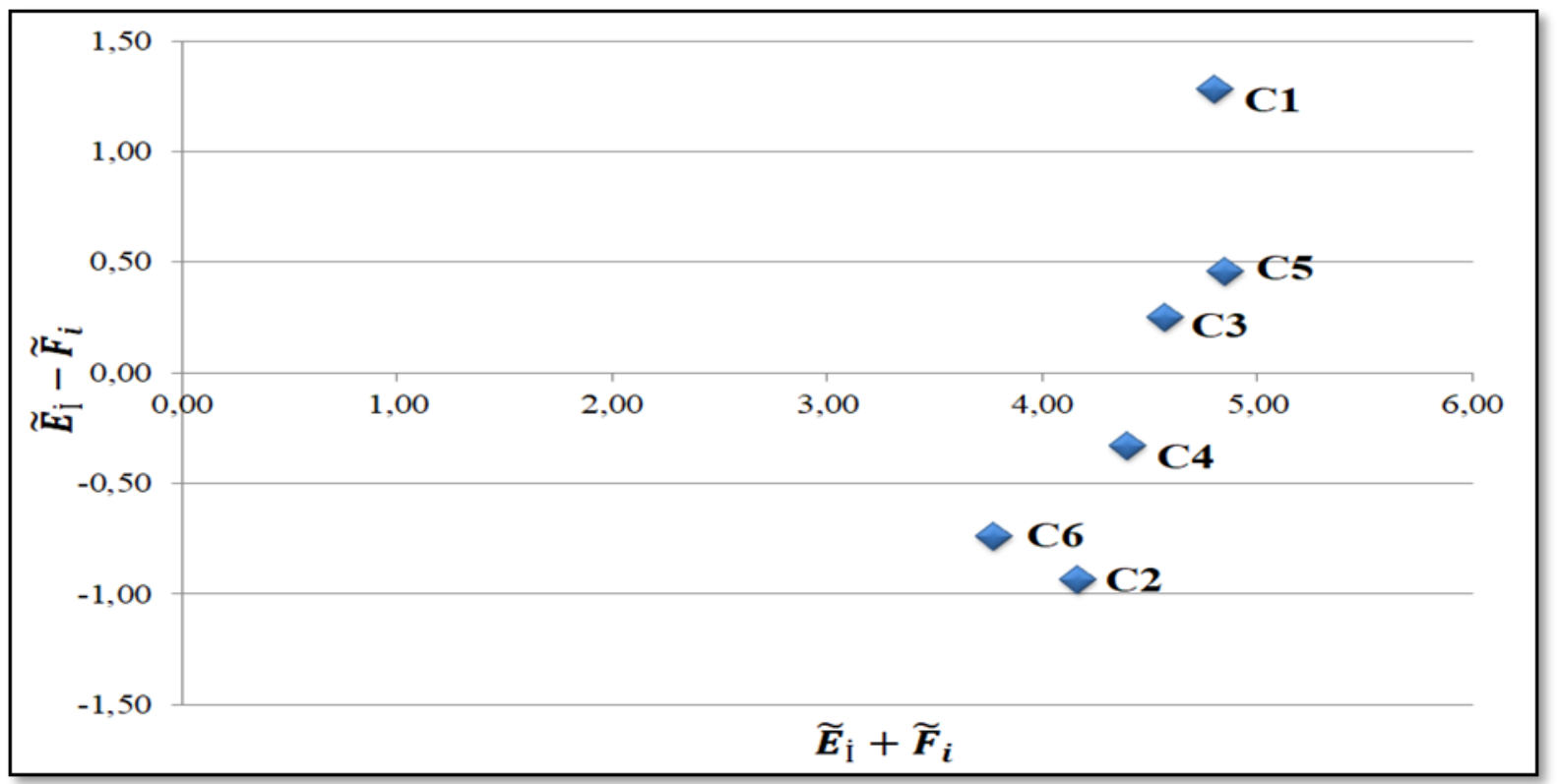

Şekil 2. Kriterlerin Etki Diyagramı 


\section{SONUÇ}

Bilgisayarlardaki ve bilgi teknolojisindeki son gelişmeler sınırsız faaliyetler içeren dünyada hem firsatları hem de zorlukları beraberinde getirmektedir. Pazarlama yöneticileri dinamik ve süreçleri birbirine bağlı olan bir uluslararası çevre ile karşı karşıya kaldıklarından dolayı dijital platformlar işletmeler için her geçen gün daha önemli bir araç haline gelmektedir. Artık birçok işletme aktif olarak ürünlerini ve hizmetlerini tanıtmak ve pazarlamak için sosyal medya platformlarını kullanmaktadır. Geleneksel pazarlama araçlarının aksine sosyal medya uygulamaları kullanıcıların yorum göndererek, bilgi paylaşarak veya ürün ve hizmetleri överek eleştirerek ve seçimlerini daha fazla kontrol etmelerine izin vermektedir. Dijital reklam, pazarlama endüstrisinde çok hızlı büyüyen bir hizmet haline gelmiştir. İşletmelerin veya ortak dijital ağların her geçen gün artarak güncellenen web siteleri, sosyal platformlar ve E-ticaret daha popüler hale geldiğinden dolayı, çevrimiçi pazarlama hizmetlerine olan talep katlanarak artmaktadır.

Geleneksel medya yok olmamakla birlikte, büyük pazarlamacıların bütçelerini yeni sosyal medya pazarlama firsatlarına ve uygulamalarına kaydırdığı açıktır. Tek yönde bilgi alışverişini içeren geleneksel pazarlama sistemi artık işletmelerin ürünlerinin tüm yönleri ile tanıtmasına ve müşterilere ürünlere/hizmetlere ihtiyaçlarının olduğunu hissettirmesine yeterince yardımcı olamamaktadır. Sosyal medya, iki yönlü iletişimi kolaylaştırır ve müşterileri kitlesel ölçekte birbirine bağlamaktadır.

Dünya genelinde birçok sosyal medya platformu mevcuttur. Bugün Türkiye'de 43 milyon Facebook, 38 milyon Instagram, 9 milyon Twitter, 7,3 milyon LinkedIn, 6,35 milyon Snapchat kullanıcısının olduğu görülmüş̧ür (Digital Global, 2019). Bu sosyal medya platformlarında Dünya genelinde verilen toplam reklam sayıs1 2,121 milyon facebook, 895 milyon instagram, 251 milyon twitter, 307 milyon snapchat ve 604 milyon linkedIn reklamı olarak karşımıza çıkmaktadır (Digital Global, 2019). Böyle büyük bir pazar ve iletişim ağında işletmelerin bu alanlarda yerlerini alması kaçınılmazdır.

Telekomünikasyon sektöründe pazarlama araçları ve kanalları yoğun olarak kullanılmaktadır. $\mathrm{Bu}$ çalışmada Telekomünikasyon sektöründe yer alan Türkiye'nin önde gelen bir işletmesinin ürünlerini ve kampanyalarını pazarlamak için sosyal medya platformunun seçiminde, seçimi etkileyen kriterlerin belirlenmesi ve kriter ağılıklarının hesaplanması amaçlanmıştır. Araştırma kapsamında hazırlanan anketler işletme bünyesinde görev yapan on sekiz pazarlama yöneticisine uygulanmıştır. Ağırlıkların hesaplanmasında Bulanık DEMATEL yönteminden, durulaştırma aşamasında ise CFCS yönteminden faydalanılmıştır. Araştırma kapsamında görünüm ve algı, içerik, maliyet, üye profili, izlenim oranı ve teknik destek olmak üzere 6 kriter belirlenmiştir. Analiz sonuçlarına göre izlenme oranı $(0,185)$, görünüm ve alg1 $(0,181)$ ve üye profili $(0,170)$ kriterleri sosyal medya platformu seçiminde en fazla ağırlığa sahip ilk üç kriter olarak karşımıza çıkmıştır. $\widetilde{E}_{\dot{I}}+\widetilde{\mathrm{F}}_{\mathrm{i}}$ değeri kriterlerin göreli önemini ifade etmektedir. $\widetilde{\mathrm{E}}_{\dot{\mathrm{I}}}-\widetilde{\mathrm{F}}_{\mathrm{i}}$ değerleri pozitif olan izlenme oranı, görünüm ve alg1 ve üye profili kriterleri diğer kriterleri etkileyen grupta yer almaktadır. Dolayısıyla bu kriterlerin, diğer kriterler üzerinde en çok etkiye sahip olduklarını söylenebilir. $\widetilde{E}_{\dot{I}}-\widetilde{\mathrm{F}}_{\dot{i}}$ değerleri negatif olan maliyet, içerik ve teknik destek kriterleri ise etkilenen grupta yer almaktadır. Etkilenen kriterler incelendiğinde ise, $\widetilde{\mathrm{E}}_{\mathrm{I}}-\widetilde{\mathrm{F}}_{\mathrm{i}}$ değeri en küçük olan maliyet kriterinin sosyal medya platform seçiminde diğer kriterlerden en çok etkilenen kriter olduğu görülmektedir.

Türkiye genelinde görev yapan telekomünikasyon pazarlama yöneticilerine yönelik gerçekleştirilen araştırma, sosyal medya seçiminde kriter ağırlıklarının belirlenmesine yönelik genel bir bakış açısı kazandıracaktır. Kriterlerin etki düzeylerinin elde edebilmesine imkan sağlayan ve aşamaları ile açıklayan bu araştırma, günümüzde birçok sosyal medya platformunu pazarlama kanalı olarak kullanan veya kullanmayı planlayan çeşitli sektörlerde yer alan işletmelerin yapacağı çalışmalara ışık tutacaktır. Farklı amaçlar için sosyal medyayı kullanmayı planlayan işletmelerin, sosyal medya platformlarını değerlendirilerek kriter ağırlıklarını belirlemesi ve bu araştırma ile karşılaştırılması, araştırmanın daha iyi anlaşılmasına yardımcı olacaktır. Ayrıca gelecek araştırmalar için araştırmacılar tarafından alternatif olarak değerlendirilen sosyal medya platformlarından hangisinin en iyi olduğuna yönelik karar verilmek istenildiğinde, hesaplanan kriter ağırlıkları kullanılarak ve çok kriterli karar verme yöntemlerinden faydalanılarak en iyi platformun seçilmesi sağlanabilecektir. 


\section{KAYNAKÇA}

Abrahams, A. S., Jiao, J., Wang, G. A. ve Fan, W. (2012). Vehicle defect discovery from social media. Decision Support Systems, 54(1), 87-97.

Ada, E., Kazançoğlu, Y. ve Aksoy, M. (2011). Esnek üretim sistemlerine etki eden faktörlerin bulanık DEMATEL yöntemi kullanılarak değerlendirilmesi. XI. Üretim Araştırmaları Sempozyumu, 23-24 Haziran.

Akın, N. G. (2017). İşletme bölümü öğrencilerinin meslek seçimini etkileyen faktörlerin bulanık dematel yöntemi ile değerlendirilmesi. Uluslararası Yönetim Ikktisat ve İşletme Dergisi, 13(4), 873-890.

Aksakal, E. ve Dağdeviren, M. (2010). ANP ve DEMATEL yöntemleri ile personel seçimi problemine bütünleşik bir yaklaşım. Gazi Üniversitesi Mühendislik-Mimarlık Fakültesi Dergisi, 25(4).

Baykasoğlu, A., Kaplanoğlu, V., Durmuşoğlu, Z. D. ve Şahin, C. (2013). Integrating fuzzy DEMATEL and fuzzy hierarchical TOPSIS methods for truck selection. Expert Systems with Applications, 40(3), 899-907.

Bertot, J. C., Jaeger, P. T. ve Grimes, J. M. (2010). Using ICTs to create a culture of transparency: Egovernment and social media as openness and anti-corruption tools for societies. Government Information Quarterly, 27(3), 264-271.

Briscoe, S. (2009). Social media at the strategic level. Associations Now: The Volunteer Leadership Issue, 75.

Büyüközkan, G. ve Öztürkcan, D. (2010). An integrated analytic approach for Six Sigma project selection. Expert Systems with Applications, 37(8), 5835-5847.

Chan, N. C. (2008). Perception of tertiary education students using blog to search for travel information. Unpublished BSc(Hons) dissertation, The Hong Kong Polytechnic University, Hong Kong.

Chen, C. T. (2000). Extensions of the TOPSIS for group decision-making under fuzzy environment. Fuzzy Sets and Systems, 114(1), 1-9.

Chou, Y. C., Sun, C. C. ve Yen, H. Y. (2012). Evaluating the criteria for human resource for science and technology (HRST) based on an integrated fuzzy AHP and fuzzy DEMATEL approach. Applied Soft Computing, 12(1), 64-71.

Chung, T. ve Law, R. (2003). Developing a performance indicator for hotel websites. International Journal of Hospitality Management, 22(1), 119-125.

Digital Global. (2019). We are social. 2 Haziran 2019 tarihinde https://wearesocial.com/uk/digital-2019 adresinden erişildi.

Doumpos, M. ve Zopounidis, C. (2002). Multicriteria decision aid classification methods. (Vol. 73). Springer Science ve Business Media.

Durugbo, C. (2012). Modelling user participation in organisations as networks. Expert Systems with Applications, 39(10), 9230-9245.

Fontela, E. ve Gabus, A. (1976). The DEMATEL observer, DEMATEL 1976 report. Switzerland Geneva: Battelle Geneva Research Center.

Gabus, A. ve Fontela, E. (1972). World problems, an invitation to further thought within the framework of DEMATEL. Switzerland, Geneva: Battelle Geneva Research Centre.

Gabus, A. ve Fontela, E. (1973). Perceptions of the world problematique: Communication procedure, communicating with those bearing collective responsibility (DEMATEL report no. 1). Switzerland Geneva: Battelle Geneva Research Centre.

Grieve, R., Indian, M., Witteveen, K., Tolan, G. A. ve Marrington, J. (2013). Face-to-face or Facebook: Can social connectedness be derived online? Computers in Human Behavior, 29(3), 604-609. 
Hsu, C. W., Kuo, T. C., Chen, S. H. ve Hu, A. H. (2013). Using DEMATEL to develop a carbon management model of supplier selection in green supply chain management. Journal of Cleaner Production, 56, 164-172.

Hwang, C.L. ve Yoon, K. (1981). Multiple Attributes Decision Making Methods and Applications. Berlin Heidelberg: Springer.

Janic, M. ve Reggiani, A. (2002). An application of the multiple criteria decision making (MCDM) analysis to the selection of a new hub airport. European Journal of Transport and Infrastructure Research, 2(2).

Kaplan, A. M. ve Haenlein, M. (2010). Users of the world, unite! The challenges and opportunities of Social Media. Business Horizons, 53(1), 59-68.

Kim, Y. A. ve Ahmad, M. A. (2013). Trust, distrust and lack of confidence of users in online social media-sharing communities. Knowledge-Based Systems, 37, 438-450.

Kotler, P., Fitzroy, P. T. ve Shaw, R. N. (1980). Australian marketing management. Australia: PrenticeHall of Australia.

Kuo, M. S. (2011). Optimal location selection for an international distribution center by using a new hybrid method. Expert Systems with Applications, 38(6), 7208-7221.

Law, R. ve Ngai, C. (2005). Usability of travel websites: A case study of the perceptions of Hong Kong travelers. Journal of Hospitality ve Leisure Marketing, 13(2), 19-31.

Li, Y. M. ve Shiu, Y. L. (2012). A diffusion mechanism for social advertising over microblogs. Decision Support Systems, 54(1), 9-22.

Lin, R. J. (2013). Using fuzzy DEMATEL to evaluate the green supply chain management practices. Journal of Cleaner Production, 40, 32-39.

Liou, J. J. ve Chuang, Y. T. (2010). Developing a hybrid multi-criteria model for selection of outsourcing providers. Expert Systems with Applications, 37(5), 3755-3761.

Liou, J. J., Tzeng, G. H. ve Chang, H. C. (2007). Airline safety measurement using a hybrid model. Journal of Air Transport Management, 13(4), 243-249.

Mangold, W. G., ve Faulds, D. J. (2009). Social media: The new hybrid element of the promotion mix. Business Horizons, 52(4), 357-365.

Meet the tweet. (2009, July). Hotels, 13-14.

McLellan, D. (2010). Social media cheat sheet. 5 Haziran 2019 tarihinde http://www.drewsmarketingminute. com/2010/03/social-media-cheat-sheet.html adresinden erişildi.

Michaelidou, N., Siamagka, N. T. ve Christodoulides, G. (2011). Usage, barriers and measurement of social media marketing: An exploratory investigation of small and medium B2B brands. Industrial Marketing Management, 40(7), 1153-1159.

Ngai, E. W. T. (2003). Selection of web sites for online advertising using the AHP. Information and Management, 40(4), 233-242.

Opricovic, S. ve Tzeng, G. H. (2003). Defuzzification within a multicriteria decision model, International Journal of Uncertainty. Fuzziness and Knowledge-Based Systems, 11(5), 635-652.

Organ, A. (2013). Bulanık Dematel yöntemiyle makine seçimini etkileyen kriterlerin değerlendirilmesi. Çukurova Üniversitesi Sosyal Bilimler Enstitüsü Dergisi, 22(1), 157-172.

Özyurt, Ö. ve Köse, C. (2010). Chat mining: Automatically determination of chat conversations’ topic in Turkish text based chat mediums. Expert Systems with Applications, 37(12), 8705-8710.

Özdemir, Ü. (2016). Bulanık DEMATEL ve bulanık TOPSIS yöntemleri kullanılarak limanlarda yaşanan iş kazalarının incelenmesi. Journal of ETA Maritime Science, 4(3), 235-247. 
Özdemir, A. İ. ve Seçme, N. Y. (2009). İki aşamalı stratejik tedarikçi seçiminin bulanık TOPSIS yöntemi ile analizi. Afyon Kocatepe Üniversitesi İktisadi ve İdari Bilimler Fakültesi Dergisi, 11(2), 79-112.

Palmer, A. ve Koenig-Lewis, N. (2009). An experiential, social network-based approach to direct marketing. Direct Marketing: An International Journal, 3(3), 162-176.

Qualman, E. (2010). Socialnomics: How social media transforms the way we live and do business. Kanada: John Wiley ve Sons.

Oussalah, M. (2002). On the compatibility between defuzzification and fuzzy arithmetic operations. Fuzzy Sets and Systems, 128(2), 247-260.

Roy, B. (1990). Decision-aid and decision-making. European Journal of Operational Research, 45(2-3), 324-331.

Scott, D. M. (2007). After thought-social media debate. EContent-Digital Content Strategies and Resources, 30(10), 64.

Shieh, J. I., Wu, H. H., ve Huang, K. K. (2010). A DEMATEL method in identifying key success factors of hospital service quality. Knowledge-Based Systems, 23(3), 277-282.

Tekez, E. ve Bark, N. (2016). Mobilya sektöründe bulanık TOPSIS yöntemi ile tedarikçi seçimi. Sakarya University Journal of Science, 20(1), 55-63.

Trusov, M., Bucklin, R. E. ve Pauwels, K. (2009). Effects of word-of-mouth versus traditional marketing: findings from an internet social networking site. Journal of Marketing, 73(5), 90-102.

Tylee, J. (2009). Adland's social revolution. UK: Campaign.

Vincke, P. (1992). Multicriteria decision-aid. Kanada: John Wiley ve Sons.

Wang, K., Wang, E. T., ve Farn, C. K. (2009). Influence of web advertising strategies, consumer goaldirectedness, and consumer involvement on web advertising effectiveness. International Journal of Electronic Commerce, 13(4), 67-96.

Wang, T. C. (2012). The interactive trade decision-making research: An application case of novel hybrid MCDM model. Economic Modelling, 29(3), 926-935.

Weber, L. (2009). Marketing to the social web: How digital customer communities build your business. Kanada: John Wiley ve Sons.

Wu, W. W. ve Lee, Y. T. (2007). Developing global managers' competencies using the fuzzy DEMATEL method. Expert Systems with Applications, 32(2), 499-507.

Wu W. W. (2008). Choosing knowledge management strategies by using a combined ANP and DEMATEL approach. Expert Systems with Applications, 35(3), 828-835.

Xiang, Z. ve Gretzel, U. (2010). Role of social media in online travel information search. Tourism Management, 31(2), 179-188.

Yager, R. R. ve Filev, D. P. (1994). Essentials of Fuzzy Modeling and Control. New York: John Wiley ve Sons.

Ye, Q., Law, R. ve Gu, B. (2009). The impact of online user reviews on hotel room sales. International Journal of Hospitality Management, 28(1), 180-182.

Zadeh, L. A. (1965). Fuzzy sets. Information and Control, 8(3), 338-353.

Zhou, Q., Huang, W. ve Zhang, Y. (2011). Identifying critical success factors in emergency management using a fuzzy DEMATEL method. Safety Science, 49(2), 243-252. 